\title{
The Rapid Dementia Screening Test (RDST): A New Economical Tool for Detecting Possible Patients with Dementia
}

\author{
Elke Kalbe $^{a}$ Pasquale Calabrese $^{\mathrm{b}}$ Susanne Schwalen ${ }^{\mathrm{c}}$ Josef Kessler $^{\mathrm{a}}$ \\ a Max Planck Institute for Neurological Research, Cologne; bUniversity Clinic, Bochum, and ' Janssen-Cilag GmbH, \\ Neuss, Germany
}

\author{
Key Words \\ Dementia · Cognitive screening · Diagnosis · General \\ practitioners
}

\begin{abstract}
The Rapid Dementia Screening Test (RDST) is a new psychometric screening tool to support the diagnosis of dementia. It includes two parts - a word generation task and a number transcoding task; it is short (taking approximately $3 \mathrm{~min}$ ) and easy to administer, and it is well accepted by patients. After transformation of the raw scores in two age groups (under and over 60 years), the assessed cognitive abilities can be interpreted as ageappropriate or below average with good sensitivity and specificity, and subsequent diagnostic measures can be determined accordingly. The RDST is thus an economical tool for detecting demented patients by general practitioners.
\end{abstract}

Copyright $\odot 2003$ S. Karger AG, Basel

\section{Introduction}

As dementia is a condition that occurs predominantly at an advanced age, its incidence will increase substantially in the coming decades as a result of the aging popula- tion and will constitute a challenge to social and financial policy-makers [1]. The diagnosis and differential diagnosis of dementia in order to enable medical and social care to be instituted at the earliest possible opportunity is thus gaining increasing importance.

Dementia, however, is often unrecognized by primary care physicians and general practitioners (GPs). As mentioned by Gifford and Cummings [2], nearly $75 \%$ of patients with moderate to severe dementia and even a higher percentage of patients with mild dementia are unrecognized by primary care physicians as having cognitive impairment. Cognitive screening instruments are useful for the detection of dementia in patients' population with an elevated prevalence of cognitive impairment either due to age or presence of memory dysfunction [3]. Nevertheless, Rubin et al. [4] found that only $12 \%$ of primary care physicians used cognitive screening tests. Brodaty et al. [5] reported a rate of $39 \%$ of GPs that performed regular screening for cognitive deficits in their older patients, but also found that the overwhelming majority of them would welcome a brief and economical screening test for identification of dementia. Next to the fact that most instruments are felt to be too time consuming, other reasons for not using screenings are the belief that the patients will be offended by the test and the GPs' lack of familiarity with neuropsychological tests [6].

\begin{tabular}{ll}
\hline KARGER & ( ) 2003 S. Karger AG, Basel \\
1420-8008/03/0164-0193\$19.50/0 \\
$\begin{array}{l}\text { Fax +4161306 12 34 } \\
\begin{array}{l}\text { E-Mail karger@karger.ch } \\
\text { www.karger.com }\end{array}\end{array}$ & $\begin{array}{l}\text { Accessible online at: } \\
\text { www.karger.com/dem }\end{array}$
\end{tabular}

Dr. Elke Kalbe

Max Planck Institute for Neurological Research

Gleueler Strasse 50, DE-50931 Cologne (Germany)

Tel. +49 2214726312 , Fax +49 2214726298

E-Mail Elke.Kalbe@pet.mpin-koeln.mpg.de 
Table 1. Description of the sample

\begin{tabular}{lllll}
\hline & & $\begin{array}{l}\text { Control group } \\
<60 \text { years } \\
\mathrm{n}=95\end{array}$ & $\begin{array}{l}\text { Control group } \\
\geq 60 \text { years } \\
\mathrm{n}=106\end{array}$ & Dementia patients \\
\hline Age, years & Mean (SD) & $52.3(4.5)$ & $71.5(8.8)$ & 659 \\
Sex & Male & 38 & 56 & 153 \\
MMSE & Female & 57 & 50 & 136 \\
& Mean (SD) & $28.3(1.5)$ & 27.8 & $22.3(5.3)$ \\
DemTect & Max 30 & & & $7.2(4.1)$ \\
& Mean (SD) & $15.3(2.8)$ & $15.4(2.7)$ & \\
& Max 18 & & & \\
\hline
\end{tabular}

According to Shulman [7], an ideal cognitive screening test should have the following qualities: (a) quick to administer, (b) be well tolerated and acceptable to patients, (c) easy to score, (d) relatively independent of culture, language, and education, (e) good inter-rater and test-retest reliability, and (f) concurrent validity and predictive validity. However, a golden standard does not exist, and in fact, the worldwide most used screening test, the Mini-Mental Status Examination (MMSE) [8], is often criticized because of its low sensitivity in mild dementia and its education and age dependency [9-11].

In this study we describe the development of a new dementia screening test that tries to fulfill the criteria outlined above, the Rapid Dementia Screening Test (RDST), and its comparison with the MMSE.

\section{Materials and Methods}

\section{Subjects}

A total of 201 control subjects (control group, CG, $n=95$ aged $<60$ years, $n=106$ aged $\geq 60$ years) who were classified as cognitively unimpaired by means of the Clinical Dementia Rating Scale $(\mathrm{CDR})$ [12] (CDR score $=0$ ) were enrolled in the study. The patient group consisted of 289 demented patients (DSM-IV) [13] with either possible Alzheimer's disease according to NINCDS-ADRDA criteria [14] or dementia with mixed etiology (vascular and neurodegenerative). All patients had mild to moderate dementia with CDR scores of 1 or 2 [12]. The study groups were comparable according to education. All patients underwent detailed neurological and psychiatric examinations including standard laboratory tests, ultrasound examination, and magnetic resonance tomography or computer tomography. An exact description of the study groups is given in table 1 .

\section{Neuropsychological Testing}

Next to the administration of the RDST tasks described below, all subjects were tested with the MMSE [8] and the DemTect [15], which is a neuropsychological screening instrument consisting of a word learning list with immediate and delayed recall, a working memory task, and the supermarket and transcoding tasks equivalent to those used in the RDST (see below). All tests were administered by study nurses or psychologists at the Neurological University Clinics of Cologne and Bochum, Germany.

\section{Selection of Subtests for the RDST}

Two tasks that are short, easy to administer and that have proven to be particularly sensitive in the psychometric diagnosis of dementia, such as in the DemTect [15], have been selected for the RDST: a semantic word generation task ('supermarket task') and a number transcoding task ('number conversion').

\section{Word Generation Task}

Word generation - or 'verbal fluency' tasks - are well-known paradigms in psychometric testing [16, 17], and testing for dementia in specific. Their main principle is that subjects have to generate words in a restricted time (usually $1 \mathrm{~min}$ ) and with restrictive search conditions with either words beginning with a specific letter (e.g. F, A, or S, so-called 'letter fluency tasks'), or words from a given semantic category (e.g. animals, tools, or things that can be bought in a supermarket, 'semantic fluency tasks'). Their high sensitivity for cognitive impairment is most probably caused by the diversity of cognitive domains that are involved, such as speed of processing (since time is limited), attention and working memory (to not repeat words within that minute), cognitive flexibility and problem-solving (for generating search strategies), imagery (as one possible search strategy), semantic memory (concerning lexical access), and language (word production) [18]. Many studies show that verbal fluency is impaired in early stages of dementia [19-22] with output changes in both quantitative (i.e. in the number of words mentioned) and qualitative ways (in the type of output). Kessler et al. [18] showed that control subjects increase their word production strategically in that, e.g. in the supermarket task, in addition to general concepts such as 'vegetables', 'drinks' or 'sweets', they frequently name examples of these categories and thus produce 'word clusters' (e.g. 'apples, pears, bananas, kiwi fruit, etc.'). Comparable strategies can be observed in letter fluency tasks, e.g. naming words with the same second letter, or produce clusters of words from a specific word class (e.g. nouns, verbs, adverbs). Due to their reduced lexical access and their lack of use of strategies, dementia patients frequently only use general concepts or form very short word clusters.

Compared to letter fluency tasks, semantic word generation is impaired earlier and more severe in demented patients [19]. From different categories tested, the supermarket task seems to be the most valuable for detecting dementia, and, in some studies, this single task that only takes 1 min could separate Alzheimer patients from con- 
trols with a sensitivity of $100 \%$ and a specificity of $89.5 \%$ [18]. The supermarket task was therefore selected for the RDST.

\section{Number Transcoding}

Numbers are a special phenomenon in language since they can be represented by many different codes, such as Arabic numbers, number words, Roman numbers and more. Thus, with respect to number processing, speakers of one specific language are all 'multilingual'. Switching from one code into the other is called 'number transcoding', and is performed in everyday life, e.g. when converting Arabic numerals to number words (as when writing a check), or transcoding number words to Arabic numerals (as when writing down a telephone number).

Number transcoding is not only impaired in patients with mainly language disturbances (i.e. aphasia) [23, 24], but also in patients with dementia. In both types of patients, mistakes are observed that can be reduced to specific language impairments, such as deficits in lexical processing (comparable to semantic paraphasias when a wrong number is used, e.g. ' 5 ' instead of ' 3 ', or ' 7 ' instead of ' 70 '), deficits in syntactic processing (when numbers are permutated, e.g. ' 23 ' for ' 32 ', or are processed term-by-term, e.g. ' $3-2-6$ ' for ' 326 '), or reading and writing difficulties. In addition to that, various studies have shown that patients with different types of dementia, such as Alzheimer's disease, vascular dementia, and Parkinson patients with dementia [25], produce specific errors that have not been observed in other brain-damaged patients. In these so-called 'shift errors' [26] or 'intrusion errors' [27], the wrong number code is used in total, or elements of one code are intruded into the other so that, for example, the number '209' becomes 2 hundred9, or ' 9,411 ' becomes 90004hundred 11 [26, examples translated from German]. Shift errors have mainly been attributed to impaired executive functioning (in special, attention and control of behavior), and a tendency to perseverate the stimulus $[27,28]$. Thus, number transcoding which is very easy to assess and easy for healthy controls, still involves various cognitive domains, such as language processing including writing and reading, number processing, and executive functions (in particular code shifting), and is therefore liable for different cognitive impairments.

For the RDST, four items for written numeral transcoding (two Arabic numbers that have to be converted into number words, and two number words to do the opposite) that in a previous study [26] have proven to cause a large number of errors in demented patients have been selected.

\section{Statistical Analysis}

All statistical analyses were carried out with the Statistical Package for the Social Sciences (SPSS) Version 10.0 for Windows (Release 10.0.7 (June 1, 2000); SPSS Inc., Chicago, Ill., USA). After checking for normal distribution of the data with the Kolmogorov-Smirnov test, we used parametric methods ( $\mathrm{t}$ tests, univariate analyses of variance, and Pearson correlations).

\section{Results}

The results of the MMSE and the DemTect are indicated in table 1 . The two tasks of the RDST take approximately $3 \mathrm{~min}$ to administer and $5 \mathrm{~min}$ including instructions and analysis. The instructions were well understood,

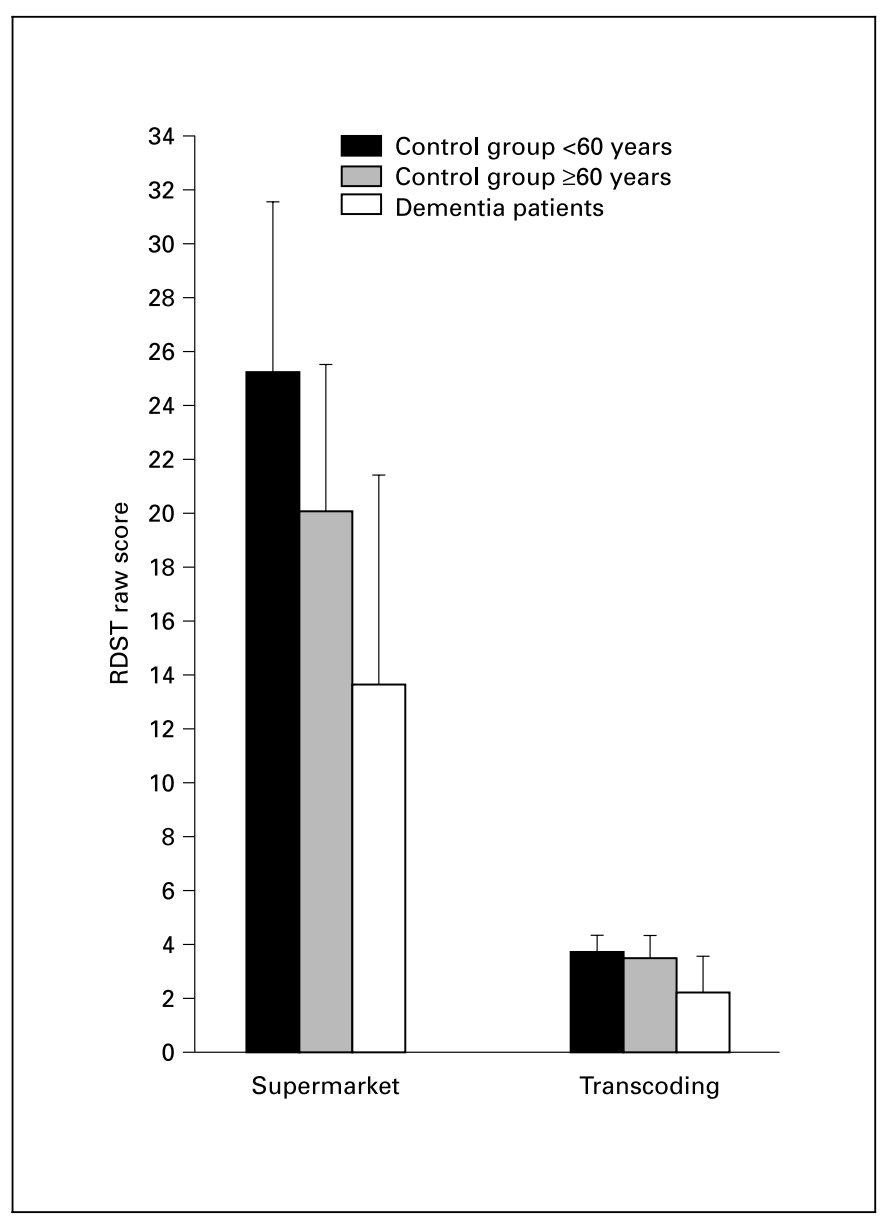

Fig. 1. Raw scores of the study groups in the two tasks of the RDST.

and the tasks were uniformly accepted by all patients, i.e. no negative feedback was given.

\section{Raw Scores in the RDST}

The RDST raw scores for the study groups are illustrated in figure 1 . In the $C G$, no effect of education was found. A significant age effect was observed for the supermarket task $(\mathrm{p}<0.001)$, but not for the transcoding task. The dementia patients scored significantly lower than both age groups of the CG.

Various errors were observed in the number transcoding task including 'shift errors' (fig. 2) that illustrate the task's sensitivity to different forms of cognitive dysfunction (both concerning language and executive function).

A discriminant analysis on the raw scores of the RDST shows an overall classification rate of $76 \%$ with a sensitivity (rate of correctly detected patients) of $70 \%$ and a specificity (rate of correctly detected control subjects) of $87 \%$. 
Fig. 2. Shift errors and other errors produced by an Alzheimer patient in performing the transcoding task of the RDST. The translation of the German items and productions are as follows: 209: two hundred and 9; 4054: four thousand and 4 on; six hundred and eighty-one: 18000 ; two thousand and twenty-seven: two thousand and 20.

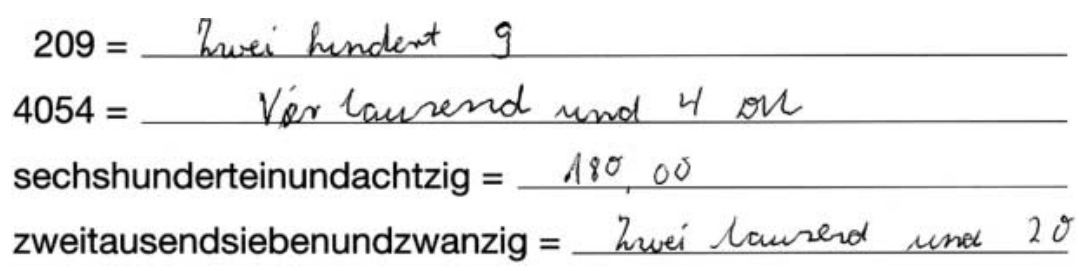

The supermarket task alone correctly classifies a total of $74 \%$ of all subjects with a sensitivity of $74 \%$ and a specificity of $74 \%$, while the transcoding task correctly classifies a total of $70 \%$ with a sensitivity of $55 \%$ and a specificity of $94 \%$.

\section{Transformation of Raw Scores, Determination of the} Test Score and Interpretation of the RDST

To increase discrimination rates of the RDST and also account for the age effect in the supermarket task, a transformation of the raw scores was defined. In a first step, the two tasks were weighted according to their sensitivity. Due to its higher sensitivity, the supermarket task was assigned twice the value of the transcoding task. A score of 4 points ( 1 point per item) was defined as the maximum score for the transcoding task and a score of 8 points with 5 levels $(0,2,4,6$ or 8 points) for the supermarket task. The RDST thus has a maximum transformed score of 12 . For the supermarket task, the ranges of the raw scores (number of correctly mentioned words) for the corresponding transformed scores were then established on the basis of the data of the CG. The maximum score of 8 was assigned to values of up to 0.5 standard deviations (SDs) below the mean score of the corresponding age group, the following classifications each being determined on the basis of 0.5 SDs. For instance, the younger age group on average produced 25 words with an SD of 6 or half an SD of 3. The full score of 8 points is thus obtained with a minimum of $25-3=22$ words minimum, 6 points with a minimum of $25-6=19$ words, etc. Accordingly, raw values more than 2.5 SDs from the mean of the age-matched control group receive a score of 0 . With this scoring procedure, the inter-rater reliability of the RDST (tested by two independent raters in a data set of 78 patients) lies at 0.93 .

The transformed scores of the samples studied are shown in figure 3. There is no significant difference between the two age groups in the CG so that the age correc- tion was successful (i.e. the RDST is age-independent after transformation of the scores). The patient group, as expected, scored significantly lower than both age groups of the $\mathrm{CG}(\mathrm{p}<0.001)$.

After determining the sensitivities and specificities of the transformed scores of the RDST at various cut-offs (see ROC curve in figure 4), a score of 9 was determined as the cut-off point between age-consistent and belowaverage performance. The overall classification rate of the RDST at this cut-off is $79 \%$ with a sensitivity of $72 \%$, a specificity of $89 \%$, a positive predictive value of $86.7 \%$ and a negative predictive value of $76.1 \%$. The likelihood ratio for a positive and negative test result are $\mathrm{L}+=6.54$ and $\mathrm{L}-=0.96$, respectively. Cognitive impairment may thus be assumed if the RDST test score is less than 9 points. In this case, detailed neuropsychological testing is urgently recommended (table 2).

While the specificity of the MMSE with a cut-off of 26 [29] is comparable to the RDST (91.5\%), it has less sensitivity $(62.5 \%)$ and a lower overall classification rate (70\%). Its positive predictive value is $88.0 \%$ and its negative predictive value is $70.9 \%$. The likelihood ratios are $\mathrm{L}+=7.35$ (positive) and $\mathrm{L}-=0.41$ (negative).

\section{Correlations with Other Screening Instruments}

The correlations of the RDST with the other screening instruments are high: $0.68(\mathrm{p}<0.001)$ with the MMSE and $0.89(\mathrm{p}<0.01)$ with the DemTect. A direct comparison of RDST and corresponding MMSE scores of all subjects is shown in figure 5 . It highlights that patients often score above the cut-off for dementia of 24 in the MMSE but below the cut-off for cognitive impairment of 9 in the RDST, while the opposite can be observed very rarely. It thus shows the higher sensitivity of the RDST. 


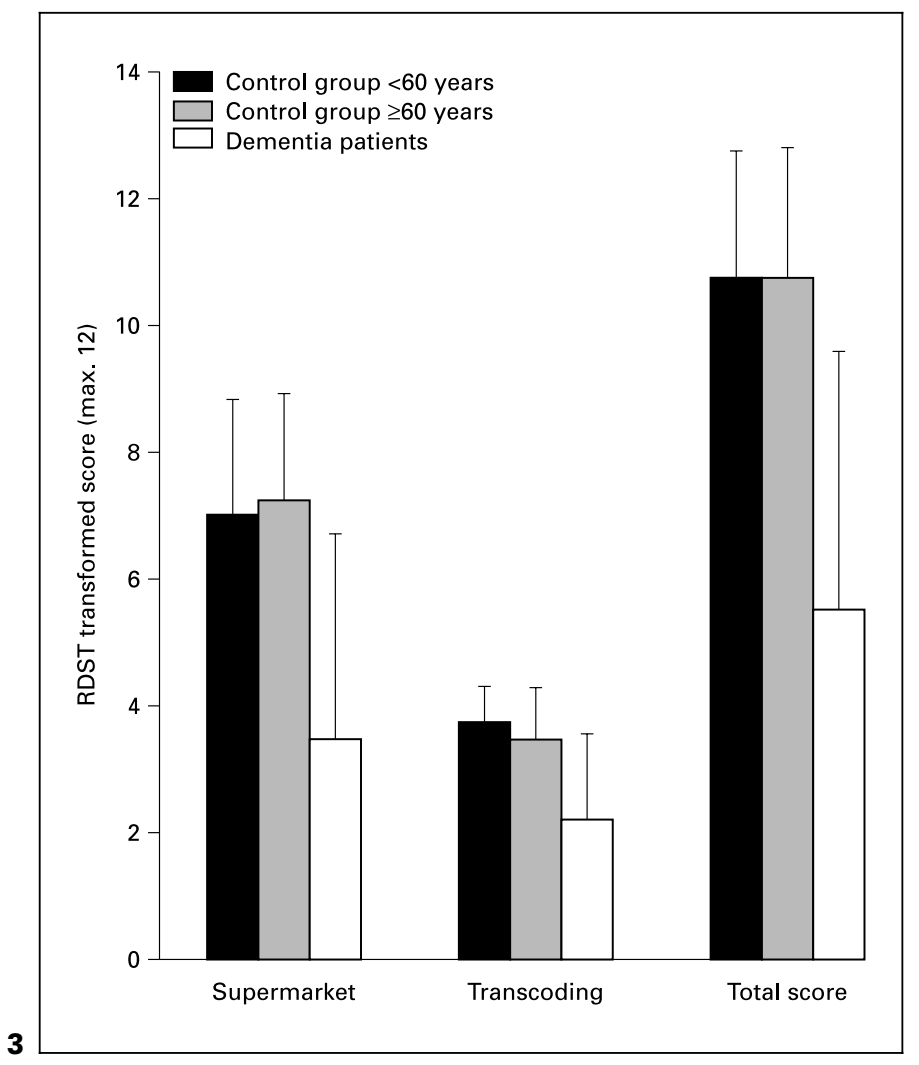

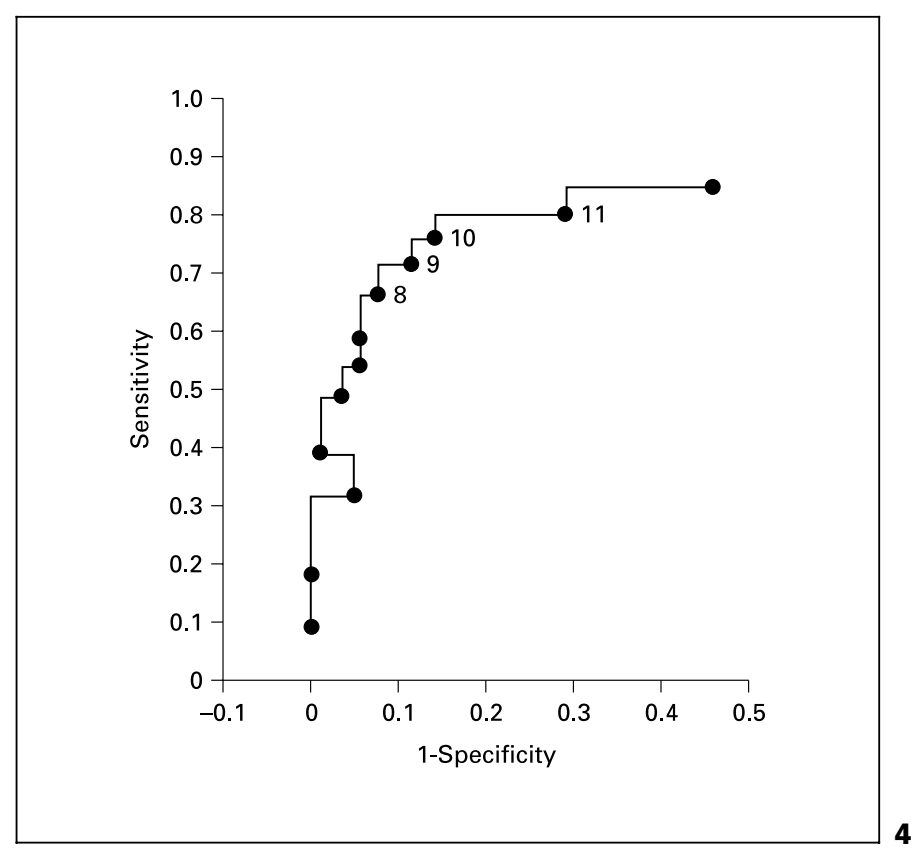

Fig. 3. Transformed scores of the study groups in the RDST.

Fig. 4. ROC curve with sensitivities and specificities of various cutoffs of the RDST.

Table 2. Interpretation of the RDST

\begin{tabular}{lll}
\hline 9-12 points & Age-appropriate performance & $\begin{array}{l}\text { In case of subjective complaints, } \\
\text { follow-up test recommended }\end{array}$ \\
$\begin{array}{l}\text { 5-8 points } \\
\leq 4 \text { points }\end{array}$ & $\begin{array}{l}\text { Cognitive impairment suspected } \\
\text { Dementia suspected }\end{array}$ & $\begin{array}{l}\text { Further diagnostic testing recommended } \\
\text { Further diagnostic testing recommended }\end{array}$ \\
\hline
\end{tabular}

\section{Discussion}

The RDST is a short (3-5 min) and thus economical, easy-to-use psychometric screening tool for identifying patients with cognitive impairment. With its two subtests - the word generation task and the number transcoding - which are well established in testing for dementia, it has high construct validity. Its sensitivity, specificity, positive and negative predictive value are satisfactory. It is independent of educational level, and with its age standards for two age groups (under and over 60 years) it is also age independent. Also, the RDST is very well accepted by the patients.

Despite comparable likelihood ratios, the MMSE is not sensitive enough in mild dementia, has no age correc- tion and can also humiliate patients with some very basic questions (e.g. Which town/city are we in?).

It should, however, be emphasized that screening procedures in general can only support a diagnosis of cognitive disorders by selecting possible patients. With their short and easy administration they are particularly suitable for a preliminary diagnosis of suspicion, which should then be followed by detailed neuropsychological testing. A screening is thus the first - but important - step in the cascade of diagnostic procedures that helps to provide early diagnosis and, most relevant, social and medical care at an early point of disease. In a recent Editorial Commentary of the Journal of Neurology, Neurosurgery and Psychiatry in 2001, Warner [30] also described the extensive advantages of an early diagnosis of dementia, 
Fig. 5. RDST scores and corresponding MMSE scores of all subjects. One spot usually represents more than 1 subject. The cutoffs for dementia and cognitive impairment defined for the two tests (see for MMSE) are outlined.

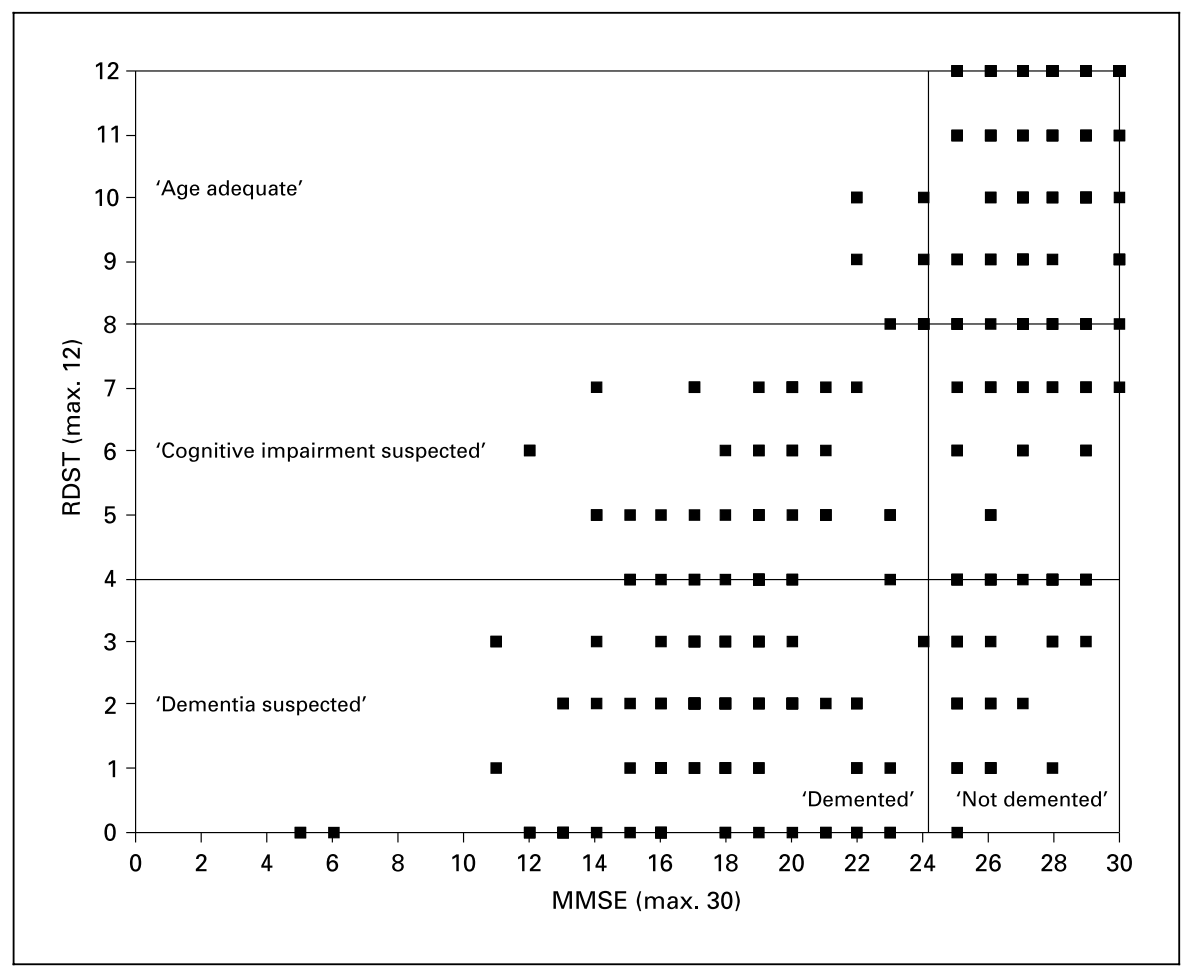

not just in relation to medical intervention: 'The ability to plan for your illness (for example, writing a will, advanced directive, and an enduring power of attorney while capacity exists), taking the trip of a lifetime, talking to estranged relatives and friends, and fulfilling other long-standing ambitions [and...] remove the atmosphere of secrecy and stigma the label still confers.'

After GPs have been convinced of the high value of using psychometric screening tools, the last important question is who should be screened. At the Buenos Aires Alzheimer's Disease International Workshop in 1995 [6] it was stated that the efficacy of and benefits from unselective use of cognitive testing and informant questionnaires for detecting early dementia in older patients attending general practice are limited. The majority view of workshop participants was that cognitive testing should occur for older patients when there is a reason to suspect dementia. Ideally, these are patients for whom informants provided a history of cognitive or functional decline (socalled 'triggering symptoms' according to Chui [31]). As a further recommendation it was stated that if screenings are embarked upon, counseling management and followthrough services must be available [6]. Newer but comparable recommendations are published in the report of Quality Standards Subcommittee of the American Acade- my of Neurology [32] and in the Evidence-Based Dementia Practice [3].

In summary, psychometric screenings are of high value in the diagnostic procedure of dementia patients. The new screening RDST which is short, simple to use, well accepted by the patients, age independent and also sensitive, represents a helpful tool to decide whether a patient's tested cognitive capacities can be regarded as age-consistent or whether a cognitive disorder may be suspected. 


\section{References}

1 Bickel H: Epidemiologie der Demenzen; in Förstl H, Bickel H, Kurz A (eds): Alzheimer Demenz - Grundlagen, Klinik, Therapie. Heidelberg, Springer, 1999, pp 9-32.

2 Gifford DR, Cummings JL: Evaluating dementia screening tests: Methodologic standards to rate their performance. Neurology 1999;52: 224-237.

3 Petersen RC, Stevens JC, Ganguli M, Tangalos EG, Cummings JL, DeKosky ST: Practice parameter: Early detection of dementia: Mild cognitive impairment (an evidence-based review). Neurology 2001;56:1133-1142.

4 Rubin SM, Glasser ML, Werckle MA: The examination of physician's awareness of dementing disorders. J Am Geriatr Soc 1987;35: 1051-1058

5 Brodaty H, Howarth GC, Mant A, Kurrle SE: General practice and dementia: A national survey of Australian GPs. Med J Aust 1994;153: 192-196.

6 Brodaty H, Clarke J, Ganguli M, Grek A, Jorm AF, Khachaturian Z, Scherr P: Screening for cognitive impairment in general practice: Toward a consensus. Alzheimer Dis Assoc Disord 1998;12:1-13.

7 Shulman KI: Clock-drawing: Is it the ideal cognitive screening test? Int J Geriatr Psychiatry 2000; 15:548-561.

8 Folstein MF, Folstein SE, McHugh PR: 'MiniMental-State' - A practical method for grading the cognitive state of patients for the clinician. J Psychiatr Res 1975;12:189-198.

9 Grigoletto F, Zappala G, Andersen DW, Lebowitz BD: Norms for the Mini-Mental State Examination in a healthy population. Neurology 1999;53:315-320.

10 Tombaugh TN, McIntyre NJ: The Mini-Mental-State examination: A comprehensive review. J Am Geriatr Soc 1992;40:922-935.
11 Lehfeld H, Ihl R, Schweitzer A, et al: Psychometrische Schweregradbeurteilung bei dementiellen Erkrankungen: Ein Vergleich von MMST, ADAS, BCRS and SKT. Z Neuropsychol 1999; 10:187-202.

12 Hughes CP, Berg L, Danzinger WL, et al: A new clinical scale for the staging of dementia. Br J Psychiatry 1982;140:566-572.

13 American Psychiatric Association, Washington: Diagnostic and Statistical Manual of Mental Disorders, ed 4. German version by Sass $\mathrm{H}$, Wittchen H-U, Zaudig M: Diagnostisches und statistisches Manual psychischer Störungen (DSM-IV). Göttingen, Hogrefe, 1996.

14 McKhann G, Drachmann D, Folstein MF, et al: Clinical diagnosis of Alzheimer's disease: Report of the NINCDS-ADRDA Work Group under the auspices of Department of Health and Human Services Task Force on Alzheimer's Disease. Neurology 1984;35:939-944.

15 Kessler J, Calabrese P, Kalbe E, et al: DemTect: Ein neues Screening-Verfahren zur Unterstützung der Demenzdiagnostik. Psycho 2000;26:343-347.

16 Lezak MD: Neuropsychological Assessment, ed 3. New York, Oxford University Press, 1995.

17 Spreen O, Strauss E: A Compendium of Neuropsychological Tests. Administration, Norms and Commentary, ed 2. New York, Oxford University Press, 1998.

18 Kessler J, Bley M, Mielke R, et al: Strategies and structures in verbal fluency tasks in patients with Alzheimer's disease. Behav Neurol 1997;10:133-135.

19 Cerhan JH, Ivnik RJ, Shmith GE, Tangalos EC, Petersen RC, Boeve BF: Diagnostic utility of letter fluency, category fluency, and difference scores in Alzheimer's disease. Clin Neuropsychol 2002;16:35-42.

20 Chertkow H, Bub D: Semantic memory loss in dementia of Alzheimer's type. What do various measures measure? Brain 1990;113:397-417.

21 Tröster AI, Salmon DP, McCullough D, Butters N: A comparison of the category fluency deficits associated with Alzheimer's and Huntington's disease. Brain Lang 1989;37:500513.
22 Monsch AU, Bondi MW, Butters N, Salmon, DP, Katzman R, Thal LJ: Comparisons of verbal fluency tasks in the detection of dementia of the Alzheimer type. Arch Neurol 1992;49: 1253-1258.

23 Deloche G, Seron X: From three to 3: A differential analysis of skills in transcoding quantities between patients with Broca's and Wernicke's aphasia. Brain 1982;105:719-733.

24 Seron X, Deloche G: From 4 to four. A supplement to 'from three to 3'. Brain 1983;106:735744.

25 Kalbe E, Kessler J: Number processing deficits and acalculia in dementia. Z Gerontol Geriatr 2002;35:88-101.

26 Kessler J, Kalbe E: Written numeral transcoding in patients with Alzheimer's disease. Cortex 1996;32:755-761.

27 Tegnér R, Nybäck H: 'Two hundred and twenty4our': The study of transcoding in dementia. Acta Neurol Scand 1990;81:177-178.

28 Kalbe E, Brand M, Kessler J, et al: Acalculia in Alzheimer's disease and other dementias - Patterns of deterioration. Neurobiol Aging 2000; 21:S231.

29 Monsch AU, et al: Improving the diagnostic accuracy of the Mini-Mental State Examination. Acta Neurol Scand 1995;92:145-150.

30 Warner J: Divining dementia. Editorial commentary. J Neurol Neurosurg Psychiatry 2001; 71:289-290.

31 Chui H: Practice guidelines; in Qizilbash N, Schneider LS, Chui H, et al. (eds): EvidenceBased Dementia Practice. Oxford, Blackwell Science, 2002.

32 Knopman DS, DeKosky ST, Cummings JL, et al: Practice parameter: Diagnosis of dementia (an evidence-based review). Report of the Quality Standards Subcommittee of the American Academy of Neurology. Neurology 2001; 56:1143-1153. 